\title{
«Votas pero no eliges»: la democracia y la crisis de la deuda soberana en la eurozona
}

\author{
"You vote but you do not choose»: democracy \\ and the sovereign debt in the eurozone
}

SONIA ALONSO

Social Science Research Center Berlin

Artículo recibido: 25 mayo 2014

Solicitud de revisión: 12 junio 2014

Artículo aceptado: 04 julio 2014

Resumen

El objetivo de este capítulo es analizar el presunto despliegue de la «democracia sin alternativas» en Europa y sus consecuencias para la calidad de las democracias nacionales, especialmente las de la periferia de la zona euro -GIIPs: Grecia, Irlanda, Italia, Portugal y España. El argumento principal es que la falta de receptividad de los gobiernos nacionales de los países GIIPs hacia los deseos de sus ciudadanos constituye el reverso de la moneda de un exceso de atención de los gobiernos de los países núcleo del euro, en especial de Alemania, a las preferencias de su ciudadanía. En todas las democracias representativas los políticos se enfrentan a un dilema fundamental entre receptividad a las demandas ciudadanas y responsabilidad ante terceros. Enfrentados a este dilema, los países núcleo del euro han optado claramente por lo primero -la receptividad ante las demandas de los electorados nacionales-, mientras que los países de la periferia de la zona euro se han visto forzados a ser responsables -ante sus socios de la uE y ante la uE en su totalidad. Como resultado, la crisis financiera de 2008 ha conducido a una ruptura en tres frentes dentro de la Unión Europea entre el núcleo y la periferia: con relación al ritmo de la recuperación económica, a los grados de autonomía gubernamental y, lo más importante, a la legitimidad democrática. Los países de la periferia de la eurozona se encuentran en el bando perdedor en los tres frentes.

Palabras clave: Eurozona, países GIIPs, euro, crisis de deuda, responsabilidad, responsiveness, legitimidad democrática.

\footnotetext{
Abstract

The objective of this article is to analyze the alleged unfolding of 'democracy without choices' in Europe and its consequences for the quality of national democracies, particularly those of the Eurozone periphery -GIIPs: Greece, Ireland, Italy, Portugal and Spain. The argument is, in a nutshell, that the lack of responsiveness of GIIPs national Governments to their respective national constituencies is the reverse of the medal of an excess of respon-
} 
siveness in core Euro countries, particularly Germany. Governments are trapped between the pressure to be responsive at home and the need to be responsible to their European partners and the European project. If the trade-off of all democratic politics is between responsiveness and responsibility, Euro core countries have clearly opted for responsiveness -to domestic constituencies- and Eurozone peripheral countries have been forced to be responsible -towards their eu partners and the eu as a whole. As a result, the 2008 financial crisis has led to a three-fold breach inside the eu between core and periphery concerning the pace of economic recovery, the degrees of governmental autonomy and, most important of all, democratic legitimacy. Eurozone peripheral countries are at the losing side of this three-fold breach.

Key words: Eurozone, GIIPs, Euro, debt crisis, responsiveness, responsibility, democratic legitimacy.

\section{INTRODUCCIÓN}

El objetivo de este capítulo es analizar el presunto despliegue de la «democracia sin alternativas» en Europa y sus consecuencias para la calidad de las democracias nacionales, especialmente las de la periferia de la zona euro -GIIPs: Grecia, Irlanda, Italia, Portugal y España. Los gobiernos de los países de la periferia están adoptando un conjunto de políticas económicas -el llamado "programa de austeridad»- que la mayoría de los ciudadanos rechaza y castiga en las urnas. La alternancia en el poder, sin embargo, no está produciendo un cambio en la política. Por lo tanto, la amenaza del castigo electoral no funciona como debería según la teoría normativa de la democracia, es decir, como medida disuasoria contra una actuación gubernamental irresponsable.

Según el punto de vista más extendido en los países de la periferia, tanto entre el gran público como por parte de las élites -incluidos los gobiernos que buscan eludir responsabilidades-, los gobiernos de los países periféricos, en tanto que miembros de la Unión Europea y de la eurozona, no tienen otra elección más que implementar el programa de austeridad, que viene impuesto sobre ellos por una combinación de instituciones europeas no electas, estados miembros acreedores y mercados internacionales.

Según la visión desde los países núcleo de la zona euro, especialmente Alemania, todos los estados miembros de la uE han estado sujetos a las mismas reglas del juego, legitimadas democráticamente a nivel nacional, ya sea por referéndum o por ratificación parlamentaria, y les ha afectado la misma crisis financiera. La diferencia entre países radica en que algunos han hecho reformas estructurales y económicas con anterioridad al comienzo de la crisis, mientras que otros han empleado los años del euro para gastar por 
encima de sus posibilidades, merced a niveles insostenibles de deuda pública y privada. Por lo tanto, la ausencia de políticas económicas alternativas a la que se enfrentan ahora los países GIIPs es una consecuencia autoinfligida de un comportamiento irresponsable previo -incluso fraudulento en el caso de Grecia.

El mantra continuamente repetido de «no hay alternativa»-TINA en sus siglas en inglés: «There Is No Alternative»- es común a los dos puntos de vista, los del núcleo y los de la periferia, pero se atribuye a causas opuestas. Para los países de la periferia, TiNa constituye una imposición foránea; para los países núcleo, tina es algo autoinfligido. Las consecuencias políticas que pueden conllevar la adopción de un punto de vista u otro no son triviales. Según la periferia, la responsabilidad de la dura situación actual recae en los países del núcleo y en las instituciones de la uE; para el núcleo, la responsabilidad es en su totalidad de los propios países GIIPS.

El problema con el punto de vista de la periferia no es tanto lo que dice, puesto que es cierto que la población de los países GIIPs no tiene realmente la posibilidad de escoger la política económica que prefiere, sino más bien lo que omite. Los gobiernos nacionales desempeñan un doble papel en la uE: el de estados miembros fundadores por separado y el de estados miembros de forma conjunta (Van Middelaar, 2013). Como Estados miembros por separado, los gobiernos nacionales representan a -y son responsables ante- sus respectivos electorados nacionales y su objetivo principal es la defensa de los intereses nacionales; como estados miembros de forma conjunta, tienen la responsabilidad de llevar a la mesa conjunta -el Consejo Europeo de jefes de estado y de gobierno- el consentimiento de sus poblaciones nacionales o parlamentos para las decisiones adoptadas conjuntamente. En otras palabras, los Gobiernos nacionales de la uE tienen dos caras, la de sus estados respectivos y la de Europa (Van Middelaar, 2013).

En sus países, sin embargo, los gobiernos de los GIIPs se sienten a menudo tentados de mostrar solo una de sus dos caras, la del estado-nación, a fin de evitar de este modo asumir la responsabilidad de lo que hacen cuando adoptan la otra cara, la europea. Se declaran impotentes ante la política económica impuesta por Bruselas y sus socios europeos, sin reconocer la parte de responsabilidad que les corresponde. El problema con el punto de vista de los países núcleo vuelve a no ser tanto lo que se dice sino lo que no se dice. Al igual que en el caso de los gobiernos nacionales de la periferia, los gobiernos del núcleo no muestran a sus ciudadanos su rostro europeo y, por lo tanto, no asumen la responsabilidad de sus actuaciones conjuntas, en tanto que estados-miembros de la UE, con los países GIIPs en 
la mesa de negociación del Consejo. El espinoso asunto de si los países periféricos hicieron lo que hicieron antes de la crisis financiera, animados por un diseño institucional del euro defectuoso, que había sido decidido conjuntamente por todos los Estados miembros, incluidos los del núcleo del euro, y mientras estos mismos países miraban para otro lado, se deja siempre en un segundo plano, ya que pertenece al rostro europeo de cada gobierno.

En resumen, el argumento que defiendo en este artículo es que la falta de receptividad de los gobiernos nacionales de los países GIIPs hacia los deseos de sus ciudadanos constituye el reverso de la moneda de un exceso de atención de los gobiernos de los países núcleo del euro, en especial de Alemania, a las preferencias de su ciudadanía, ignorando las interdependencias existentes entre los estados miembros de la uE. Entre el electorado de los países núcleo, se tiene la impresión de que los problemas de la periferia no son de su incumbencia, que sus gobiernos nacionales no tienen responsabilidad en el despliegue de la crisis en curso y que, en consecuencia, no son responsables de dichos problemas. Las democracias periféricas de la zona euro están sometidas a mucha presión, precisamente porque la legitimidad de las democracias del núcleo se fortalece bajo la aplicación de la austeridad en los países azotados por la crisis. El problema es que es imposible responder a la vez a estos dos grupos de demandas desde abajo, opuestas y contradictorias: las demandas populares a favor de la austeridad entre la ciudadanía de los países núcleo, cansada de sacar de apuros al resto, y las demandas de expansión fiscal entre la población de la periferia, hastiada de tanta austeridad. Debe darse prioridad a uno de estos dos electorados europeos con intereses contrapuestos y, en el mundo predominantemente intergubernamental de la uE, son los votantes de los estados miembros económicamente más fuertes quienes se imponen y lo hacen a favor de la austeridad.

En todas las democracias representativas, los políticos se enfrentan a un dilema fundamental entre receptividad a las demandas ciudadanas y responsabilidad ante terceros. Enfrentados a este dilema, los países núcleo del euro han optado claramente por lo primero -la receptividad ante las demandas de los electorados nacionales-, mientras que los países de la periferia de la zona euro se han visto forzados a ser responsables -ante sus socios de la UE y ante la uE en su totalidad. El presidente de el gobierno de España, Mariano Rajoy, lo expresó sin rodeos en una conferencia de prensa: «No he cumplido mis promesas, pero sí con mi deber» (El País, 13/2/2013). Como resultado, la crisis financiera de 2008 ha conducido a una ruptura en 
tres frentes dentro de la Unión Europea entre el núcleo y la periferia: con relación al ritmo de la recuperación económica, a los grados de autonomía gubernamental y, lo más importante, a la legitimidad democrática. Los países de la periferia de la eurozona se encuentran en el bando perdedor en los tres frentes.

\section{DEMOCRACIA, ALTERNATIVAS Y LA AUTONOMÍA DE LOS GOBIERNOS}

La democracia consiste en elegir entre distintas alternativas. Ni siquiera las llamadas concepciones minimalistas de la democracia pondrían objeciones a esto: «El único sistema de votación democrático es aquel que facilita la elección de los ciudadanos» (Riker, 1982: 5). Ante la ausencia de elección entre alternativas programáticas, votar solo sirve para «ratificar elecciones que se han realizado en otro lugar» (Przeworski, 2010: 117). Toda la lógica de la competición electoral anima a los partidos a ofrecer plataformas alternativas durante las elecciones con el fin de maximizar sus votos. Incluso cuando la estructura de la competición electoral conduce a los partidos a intentar atraerse hacia sí el votante mediano, la lógica de la votación generalmente impide que las plataformas de los partidos sean completamente idénticas (Downs, 1957: 41-45). La teoría del gobierno de partido responsable se basa, de forma aún más explícita, en la idea de que las elecciones proporcionan a los votantes alternativas claras entre las que elegir. Los partidos compiten en las elecciones representando diferentes plataformas políticas entre las que los votantes escogen, y el partido que sale elegido ejerce su mandato: «Esta congruencia entre la promesa y la actuación se encuentra en el centro de lo queremos decir con "democracia” (Klingemann, Hofferbert y Budge, 1994: 2).

La elección en democracia no pertenece exclusivamente al momento electoral; los gobiernos electos también deben ser autónomos, para actuar durante su mandato eligiendo entre rutas políticas alternativas. La teoría económica de la democracia de Downs presupone un gobierno que «sea capaz de llevar a cabo las funciones sociales del gobierno" (1957: 21). Downs escribía a mediados de los años 50, antes del giro neoliberal de la economía mundial, por lo que es evidente que estaba pensando fundamentalmente en restricciones internas a la autonomía de los gobiernos. Los economistas y politólogos llevan desde entonces redirigiendo su atención hacia las restricciones externas. Existen tres fuentes principales de cons- 
treñimientos externos: la globalización, la propagación de las creencias neoliberales y las organizaciones supranacionales.

La globalización cambia el equilibrio entre los costes y los beneficios adscritos a diversas alternativas de acción política (Held, 2000: 423) y, por ese motivo, constituye un factor importante de limitación de la autonomía gubernamental (Rodrik, 2011; Stiglitz, 2012; Chang, 2012). La política económica es probablemente el área política que se ha visto más afectada por la última ronda de internacionalización de los mercados nacionales. La globalización «limita hasta qué punto la democracia puede perseguir políticas populistas y muy mayoritarias» (Acemoglu y Robinson, 2006: 40). Esto «implícitamente excluye la elección como parte de la política» (Judt, 2010: 193). La integración de los mercados está concebida para influir en la autonomía de los gobiernos nacionales mediante tres mecanismos básicos: las presiones hacia una mayor competitividad comercial, la multinacionalización de la producción y la integración de los mercados financieros (Garrett, 1999: 793). Según Garrett, la integración de los mercados financieros es, de estos tres, el mecanismo que más limita las opciones de los gobiernos nacionales (Garrett, 1999: 823). El poder de los mercados financieros mundialmente integrados reside en el hecho de que «si las políticas e instituciones que desean los mercados no se encuentran en un país, el dinero saldrá a borbotones hasta que se encuentren» (Garrett, 1999: 793).

Algo que limita la autonomía gubernamental aún más que la globalización es la idea neoliberal de que, para que la política económica sea óptima, ésta debe protegerse de la tentación de los políticos democráticos de responder a las preferencias de los votantes. Es lo que Friedman (2012) llamaba la «camisa de fuerza dorada». Existe abundante literatura en economía y ciencia política que defiende la necesidad de aislar a los políticos de las demandas de los ciudadanos. Dos son los mecanismos básicos que se han empleado para aislar la política económica de las demandas de los ciudadanos. Por una parte, la instauración de reglas fijas de comportamiento que limiten o eliminen el criterio gubernamental y, por otra, la delegación de la política económica en agencias públicas independientes del control político, como los bancos centrales. Este debate nos remite de nuevo al dilema que subyace a toda política pública en democracia entre, por un lado, priorizar la responsabilidad frente a terceros, o, por otro lado, dar satisfacción a las demandas ciudadanas, lo que, en última instancia, nos lleva al reto más inquietante: lograr que el capitalismo y la democracia sean compatibles.

El tercer factor, y el que probablemente más limita la autonomía gubernamental, es la pertenencia a la Unión Europea, puesto que ésta combina un 
marco institucional neoliberal -reglas fijas de política fiscal y delegación de la política monetaria en un banco central independiente- con mercados plenamente integrados. A ello me referiré con detalle en los apartados siguientes.

En resumen, una democracia merecedora de tal nombre es aquella en la que se ofrecen alternativas bien diferenciadas entre las que los ciudadanos puedan elegir, y en la que los Gobiernos tienen el poder efectivo de llevar a cabo las políticas para las que han resultado elegidos. Además, en una democracia que funciona es «muy poco probable que un Gobierno lleve a cabo durante mucho tiempo políticas que ofendan profundamente a la mayoría de los ciudadanos»(Dahl, 1989: 223). Si las restricciones externas a la autonomía de los Gobiernos nacionales fueran tales que, a pesar de hacer promesas electorales claramente diferenciadas, los gobiernos elegidos tuvieran que aplicar las mismas políticas, «los ciudadanos votarían, pero no elegirían» (Maravall, 2013:169).

\section{LA UNIÓN EUROPEA: UNA «CAMISA DE FUERZA DORADA»}

La idea inicial detrás de la creación del mercado único europeo era que la unión económica podría llevar eventualmente a una unión política ${ }^{1}$, pero esta expectativa nunca llegó a materializarse. El euro es, por lo tanto, «una moneda sin Estado» (Panagiotarea, 2013). Los gobiernos nacionales de la zona euro tienen incentivos para priorizar la receptividad hacia sus electorados nacionales más que la responsabilidad hacia sus socios de la eurozona y la ue en su conjunto.

\subsection{Las reglas del juego}

La Unión Europea está diseñada de acuerdo con la creencia neoliberal de que se debe proteger a los políticos de sus instintos electoralistas. El mundo de Maastricht es un «mundo de reglas estrictas e imparciales, un monumento vivo a la sabiduría liberal de mercado» (Martino 2008: 267). La autonomía gubernamental de los estados miembros de la Unión Europea en materia de política monetaria y fiscal está limitada por el uso de dos instrumentos principales: el Pacto de Estabilidad y Crecimiento (PEC) y la

1 «Igual que la unión aduanera tenía que preceder a la integración económica, la integración económica tiene que preceder a la unidad europea» (Comisión Europea, Completing the Internal Market. White Paper from the Commission to the European Council, COM (85)310, 14 de junio de 1985). 
Unión Monetaria Europea (UEM) bajo el control del Banco Central Europeo (BCE).

Por lo que respecta a la política fiscal, los 27 Estados miembros se convierten automáticamente en miembros del PEC. El objetivo principal del pacto es el equilibrio fiscal. El criterio de los gobiernos debe limitarse mediante reglas externas fijas: una relación máxima de déficit presupuestarioPIB del 3 \% y una relación máxima de deuda soberana-PIB del $60 \%$.

El BCE establece la política monetaria para todos los países de la eurozona. Los términos de funcionamiento del BCE se basan en tres principios: independencia, un mandato único centrado en la estabilidad de los precios y la prohibición de financiar los déficits presupuestarios de los miembros de la UE -la cláusula de no corresponsabilidad financiera. La combinación de una autoridad independiente que establece la política monetaria y de la adhesión al euro conlleva varias implicaciones para la autonomía política de los gobiernos nacionales. En primer lugar, compartir la misma moneda equivale a tener tipos de cambio fijos. Los gobiernos nacionales de la eurozona no pueden emprender una devaluación externa para aumentar la competitividad de los productos nacionales. La única variable de ajuste que queda para abrir mercados competitivos son los salarios.

En segundo lugar, los gobiernos nacionales de la zona euro que desean recibir préstamos para poder aumentar el gasto público, aunque quieran hacerlo dentro de los límites del PEC, tienen que hacerlo en una moneda que no controlan. Si quieren disponer de préstamos, tienen que acudir al mercado abierto y competir con las empresas para obtener crédito. Esto deja a los gobiernos de la eurozona a merced de los mercados internacionales.Además, declararse en bancarrota y faltar al pago de las deudas no es una opción dentro de la UEM.

En tercer lugar, los gobiernos nacionales de la zona euro están sujetos a la misma política monetaria independientemente de las condiciones y necesidades de sus economías nacionales. Esto es lo que se llama monetarismo «de talla única». El BCE establece los tipos de interés nominales válidos para todas las economías de la eurozona. Si el nivel de inflación es diferente en cada país, como de hecho es, los tipos de interés reales variarán acordemente, bajando para aquellos países con niveles más altos de inflación y viceversa. 


\subsection{Margen de maniobra}

El PEC y las reglas del BCE fijan los términos dentro de los cuales pueden moverse los gobiernos nacionales. En consecuencia, durante los periodos de contracción económica, los gobiernos nacionales tienen una discrecionalidad limitada a la hora de aplicar sus propias soluciones para salir de la situación. Pero ¿hasta qué punto limitan estas reglas realmente la autonomía de los gobiernos? Para responder a esta pregunta, hemos de saber, en primer lugar, hasta qué punto los gobiernos nacionales son obligados a respetar estos límites y, en segundo lugar, cómo son de razonables estos límites o, en otras palabras, en qué medida los gobiernos nacionales pueden, respetando estos límites, hacer frente a la mayor parte de situaciones de crisis con las que suelen encontrarse los países.

Comencemos con la imposición del PeC a los Estados miembros. En caso de incumplimiento, la Comisión Europea inicia un procedimiento de déficit excesivo -PED- para forzar a los gobiernos nacionales a volver al redil. En la práctica, el cumplimiento de esta norma ha sido escaso. Solo hay un país que nunca ha sobrepasado el límite de déficit -Estonia-; respecto al límite de deuda, solo cinco países no lo han superado nunca -Estonia, Finlandia, Luxemburgo, Eslovaquia y Eslovenia- Alemania y Francia se encuentran entre los primeros en infringir el Pacto en 2001 y 2002, respectivamente -Comisión Europea, Asuntos Económicos y Monetarios.

La débil aplicación del pacto desde su nacimiento nos indica que, de facto, la supuesta restricción a la discrecionalidad gubernamental debería interpretarse, más bien, como el resultado de decisiones políticas, no tecnocráticas; pertenece a lo que Van Middelaar denomina la «esfera intermedia de los Estados miembros» (2013:18) y sus relaciones mutuas de poder, no a la «esfera interior» de las instituciones de la UE -Comisión y Parlamento. Hacer cumplir las normas ha dependido no solo de la situación macroeconómica de un país -la decisión tecnocrática, igual para todos-, sino también de las consideraciones políticas no incluidas en el pacto -la decisión política, que resulta del poder de cada Estado miembro para imponer su punto de vista. En suma, una aplicación débil y sanciones suaves convirtieron «la política económica en algo "nacional" y, por lo tanto, susceptible a los cálculos políticos habituales» (Panagiotarea, 2013: 163).

Por lo tanto, la existencia de restricciones a la discrecionalidad gubernamental para decidir la política económica no equivale a una carencia total de capacidad de elección. Una imposición poco enérgica de las reglas ha garantizado, al menos hasta 2012, un gran margen de maniobra a los 
gobiernos nacionales, precisamente como los estados miembros querían que fuera, puesto que tenían que responder ante sus electorados nacionales (Van Middelaar, 2013).

Dada la diversidad de condiciones económicas, por un lado, y las diferencias entre los gobiernos en lo que respecta a su voluntad de incurrir en déficits presupuestarios, por el otro, la discrecionalidad gubernamental quedó reflejada en el amplio abanico de políticas que se pusieron en práctica como respuesta a la crisis financiera de 2008: algunos confiaron en la expansión fiscal activa, otros esperaron a que los estabilizadores automáticos de la economía comenzaran a hacer efecto sin intervención, otros aplicaron medidas procíclicas, y todo ello con diferentes resultados (Ansell, 2012; Armingeon y Baccaro, 2012; Barnes y Wren, 2012; Cameron 2012). Algunos países salieron de la recesión mucho antes que otros y con menos costes sociales, lo que aumentó los desequilibrios económicos dentro de la uE (Cameron, 2012: 124).

La crisis llevó a la mayoría de las economías europeas a infringir los límites del PEC. En diciembre de 2009, entre los veintisiete estados miembros, había veinte procedimientos de déficit excesivo abiertos. Ante el riesgo de convertir las normas de Maastricht en papel mojado, y presionado por Alemania, la reacción del Consejo Europeo fue establecer un nuevo pacto fuera del Tratado -y, por lo tanto, un pacto intergubernamental-, el llamado Pacto Presupuestario, que es más estricto que su predecesor, en cuanto a que supervisa a los países más de cerca, permite la aplicación automática de medidas contra los que eluden responsabilidades y requiere que todos los países firmantes -el Reino Unido y la República Checa no se adhirieron al pacto- aprueben una ley constitucional que los obligue al equilibrio fiscal -Schuldenbremse o freno a la deuda.

El Pacto Presupuestario se firmó el 2 de marzo de 2012 y entró en vigor el 1 de enero de 2013. El resultado es que la camisa de fuerza de la ue apretará aún más a partir de ese momento, la autonomía de los gobiernos nacionales se verá aún más reducida y la política económica se verá aún más alejada de la rendición de cuentas democrática. Una vez más, esta limitación a la discrecionalidad de los Gobiernos nacionales ha sido autoinfligida y, una vez más, se ha tratado de una respuesta política a una situación económica. Como lo ha expresado Schelkle: «El nuevo marco normativo abdica del poder político, refuerza las presiones económicas y permite que los mercados dicten las elecciones en torno a políticas, aunque sean manifiestamente contraproducentes e incoherentes» (2012: 151). Los países núcleo de la eurozona no sienten el efecto del Pacto Presupuestario todavía, pues- 
to que sus economías están recuperándose a paso lento de la crisis económica, pero es posible que algún día lo hagan.

La mayoría de los gobiernos nacionales de la uE, en un momento u otro, no han encontrado espacio para respirar dentro de los límites fiscales y monetarios de la UE, como demuestra la gran cantidad de PED iniciados desde 2000. No es simplemente una consecuencia de la crisis financiera de 2008, dado que el número de PED ya era alto antes de iniciarse ésta. Los límites de deuda y déficit de Maastricht demostraron haber sido demasiado estrictos desde su creación. Incluso el país que apoyaba más plenamente las reglas monetarias y fiscales fijas, Alemania, tuvo que admitir su inflexibilidad durante los años que siguieron a la firma del PEC. Con todo, en lugar de avanzar hacia un diseño de reglas más flexibles o de cuestionar la necesidad de reglas en general como reacción a la crisis, los líderes europeos están yendo hacia reglas más estrictas y hacia una política económica cada vez más inflexible -mayor tecnocracia, menor autonomía para la política.

\section{LA CRISIS DE LA DEUDA SOBERANA}

La introducción de la Unión Económica y Monetaria -uEM- precedió la convergencia económica entre las economías de la uE y no vino acompañada por una unión fiscal simultánea. Como era de esperar en estas circunstancias, la unión monetaria no sólo no eliminó los desequilibrios económicos ya existentes en la UE, sino que creo algunos nuevos (Scharpf, 2011). Por lo tanto, cuando la crisis económica golpeó a los países de la UE a finales de 2008, la gran variación de respuestas fiscales nacionales sólo sirvió para acentuar aún más los desequilibrios económicos ya existentes entre los países.

\subsection{Divergencia núcleo-periferia antes de 2008}

Esta historia es de sobra conocida y se ha contado muchas veces. Durante la década de los 90 y en los primeros años de la década posterior, el crecimiento económico en la periferia de la eurozona provenía principalmente de la expansión del consumo privado financiado por un progresivo endeudamiento en el sector privado -y público, en el caso de Grecia. El crédito era barato, puesto que los tipos de interés reales en las economías de los países GIIPs eran muy bajos en comparación con los de las economías del 
núcleo del euro. Lo que se suponía que era una política monetaria conservadora impuesta por el BCE se convirtió de facto en una política monetaria expansionista en los países GIIPS ${ }^{2}$. En España e Irlanda, este crédito barato financió una burbuja inmobiliaria que impulsó el crecimiento económico, junto con el empleo, los ingresos per cápita y los precios. En Grecia, la deuda pública se empleó para políticas de expansión fiscal. Los salarios y los costes laborales unitarios reales aumentaron de manera acorde, lo que dio como resultado un crecimiento de las importaciones y un descenso de la competitividad, así como un aumento de la desigualdad entre el núcleo y la periferia.

Por todas las razones anteriormente expuestas, las economías de los GIIPS se mostraron especialmente vulnerables a la crisis financiera de 2008 , característica que compartían con otros países de la ue, como, por ejemplo, el Reino Unido. Lo que diferenciaba al Reino Unido de los países GIIPs era la adhesión al euro. De no haber estado sometidas a las rigideces del euro, las historias de las economías de los países GIIPS podrían haberse parecido mucho más a la del Reino Unido (Armingeon y Baccaro, 2012).

Indudablemente, los gobiernos de los GIIPS podrían haber hecho mejor uso de la limitada discrecionalidad que tenían, durante el periodo de crecimiento económico que precedió a la crisis financiera de 2008. Como bien ha señalado Scharpf, los programas políticos de choque implementados en la periferia europea con el fin de cumplir con los criterios de Maastricht «no abordaron las diferencias institucionales y estructurales subyacentes que habían sido la causa original de la divergencia económica» con el resto de Europa (Scharpf, 2011: 12). El problema, no obstante, no era de despilfarro fiscal en todos los países GIIPS, como normalmente aducen los políticos y los medios de comunicación de los países núcleo de la zona euro. Irlanda y España habían estado produciendo superávit desde 2003 y 2005 , respectivamente, y sus niveles de deuda pública se habían mantenido por debajo del $60 \%$ desde el establecimiento del euro. Portugal tenía niveles igualmente bajos de deuda pública. La rectitud fiscal no salvó ni a Irlanda ni a España de necesitar ayuda financiera.

2 Los tipos de interés reales medios entre 1996-2007 en Alemania (3,9\%), Finlandia (3,4 \%), Austria $(3,5 \%)$ o Francia (3 \%) eran mucho mayores que en Grecia $(2,3 \%)$, Portugal $(1,8 \%)$ o España $(1,4 \%)$. 


\subsection{La austeridad entra en juego}

La respuesta inicial al colapso financiero y a la subsiguiente crisis económica en las economías occidentales desarrolladas fue la aplicación de políticas anticíclicas, en forma de paquetes fiscales expansionistas. Las excepciones a esto fueron Irlanda y Grecia (Bermeo y Pontusson, 2012), pero el keynesianismo no duró mucho tiempo en los países de la eurozona. Después de un año de expansión fiscal en Alemania, era imprescindible para el gobierno volver a la rectitud fiscal, eje de la campaña con que ganó las elecciones. Justo en el momento en que el Gobierno alemán estaba preparado para abandonar los estímulos fiscales, estalló la crisis de la deuda en Grecia. En octubre de 2009, inmediatamente después de la victoria aplastante de PASOK en las elecciones griegas, el nuevo ministro de Finanzas, Papaconstantinou, reconoció públicamente que el déficit presupuestario alcanzaría el 12,5\% de PIB a finales de ese año, superando en más del doble las previsiones del gobierno anterior.

Es precisamente entonces cuando la ortodoxia en torno a la austeridad entró en escena. Obedeciendo al EcoFin, a principios de febrero, el gobierno griego anunció un paquete de austeridad que se esperaba que redujera el déficit al $3 \%$ del PIB en 2012. Un mes después, en marzo de 2010, cuando S\&P redujo la calificación de la deuda soberana de Grecia a BвB+, el primer ministro Papandreou se vio obligado a pedir ayuda a sus socios de la UE. El interés de los bonos a diez años de Grecia había alcanzado entonces el 9,68\%. En mayo, los miembros de la eurozona acordaron un préstamo de 110000 millones de euros a tipos de interés de mercado -Euríborpara salvar a Grecia.A cambio, el gobierno griego se comprometió a realizar recortes por valor de 30.000 millones de euros durante los tres años siguientes.

La crisis griega infectó pronto al resto de economías más frágiles de la eurozona. Irlanda y Portugal habían estado aplicando las medidas de austeridad desde el estallido de la crisis financiera en 2008, pero este hecho no les protegió de una intervención europea pocos meses después de la de Grecia. España dio un giro de $180^{\circ}$ pasando de la expansión fiscal a la austeridad en mayo de 2010 , después de la primera crisis griega, en un anuncio que le costaría la carrera política al presidente del Gobierno, José Luis Rodríguez Zapatero. Pero, al igual que pasó con Irlanda y Portugal, la austeridad no salvaría a España de caer en desgracia con los mercados.

A pesar de los enormes esfuerzos encaminados a lograr la rectitud fiscal, los mercados siguieron desconfiando de los bonos de los países girPs y de 
su capacidad para pagar sus deudas. La austeridad estaba generando los resultados contrarios a los pretendidos. Los predicadores de la austeridad olvidaron convenientemente el hecho de que políticas fiscales procíclicas fuertes en este contexto podían activar una espiral de recesión (Krugman, 2009; Stiglitz, 2010; Scharpf, 2011; Cameron, 2012), pero la realidad se impuso y la espiral de recesión pronto hizo acto de presencia.

Cuando un país de la eurozona no puede seguir pidiendo préstamos en los mercados de deuda internacionales y ni quiere ni puede dejar de pagar sus deudas declarándose en bancarrota, la austeridad es la única opción, ya que es la única política que los prestamistas aceptarán como condición para conceder el crédito. Cualquiera que haya leído los Memorandos de Acuerdo - MDA- firmados por los países deudores de la uE y sus acreedores -la llamada Troika: los estados miembros de la uE representados por la Comisión Europea, el BCE y el FMI- comprenderá que estos acuerdos han sustituido a los programas electorales de los partidos en tanto que hojas de ruta de la política nacional. Estos acuerdos especifican la política económica del país de manera muy detallada. Los MDA son contratos que vinculan a los gobiernos electos del futuro. Si los países no actúan como marca el acuerdo, no obtendrán el dinero que necesitan, que, por otra parte, se dedica cada vez más al pago de intereses de la deuda y no a la administración de los estados. Los ciudadanos de los países GIIPs, por tanto, votan en las elecciones, pero no eligen entre políticas económicas alternativas, porque la política económica ya viene determinada por el MdA. El presidente del Gobierno de España, Mariano Rajoy, admitió esto sin rodeos ante el Parlamento español el 10 de julio de 2012: «Los españoles no podemos elegir, no tenemos esa libertad» (El País, 11/7/2012). Lo que no dijo es que, aunque no hay alternativa dentro del marco de los MDA y de la UEM, nada ni nadie estaba limitando la capacidad del gobierno español de movilizar el apoyo, tanto dentro del país como entre sus socios europeos, contra la ortodoxia de la austeridad y a favor de una completa renegociación del pacto de la UEM.

El mantra de TINA sólo es cierto dentro de los sólidos muros de la UEM. Sin embargo, las normas de la UEM no son más sagradas que cualquier otro conjunto anterior de reglas que los miembros de la uE se han dado a sí mismos y que después han decidido cambiar para avanzar hacia el proyecto europeo. De lo que no hay duda es que todas las alternativas políticas a la austeridad que se propongan deben confrontar directamente el problema de las reglas monetarias y fiscales de la UEM actualmente en vigor. Los problemas de distribución de costes y beneficios entre países deudores y 
acreedores, que subyacen a la crisis de la deuda soberana, tienen que reconocerse y tratarse de forma explícita. Los Gobiernos GIIPs se están centrando en renegociar los MDA, intentando ampliar los plazos de cumplimiento, conscientes, sin embargo, de que el cumplimiento significa, incluso con plazos más flexibles, la pérdida de al menos una generación en sus respectivos países. La elección que existe, por tanto, no gira en torno a políticas económicas alternativas, puesto que sólo hay una alternativa sobre la mesa dentro de las normas de la uEm. La elección gira en torno a si se aceptan estas reglas del juego o si es necesario renegociarlas. La elección es, una vez más, de naturaleza política, no económica, y tiene consecuencias fundamentales para el futuro del euro y de la Unión Europea en su conjunto.

\section{ELECCIONES Y ELECCIÓN}

Schattschneider escribió en 1975 que «la definición de las alternativas es el instrumento supremo del poder» (1975: 68). La crisis de la deuda soberana en Europa lo ilustra muy bien. La elección se reduce de forma artificial a dos únicas alternativas por parte de aquellos que ocupan puestos de poder: austeridad o colapso económico, euro o anarquía. De acuerdo con este punto de vista, el rechazo de los Memorandos de Acuerdo se incluye en la segunda categoría, la de colapso económico y anarquía. Esta reducción de las alternativas a sólo dos tiene un doble propósito. Por una parte, reduce el espacio político a su mínima expresión. Una de las alternativas es tan incierta y se asume que sus consecuencias son tan costosas que en realidad la elección se reduce a una sola alternativa: la austeridad. Por otra parte, sirve para deslegitimar como irresponsables y populistas a todos aquellos partidos políticos y movimientos sociales que creen que existe una alternativa a la austeridad.

La alternancia en el poder no puede producir un cambio político en los países sometidos a las normas de los MDA. Es cierto que, incluso antes de firmar los acuerdos con la Troika, los Gobiernos de los GIIPs ya habían puesto en práctica medidas de austeridad por iniciativa propia. A partir de la firma de los MDA, los Gobiernos de los países GIIPs están comprometidos por el acuerdo a aplicar las medidas de austeridad, independientemente de la ideología del gobierno de turno. La diferencia es sutil pero fundamental desde el punto de vista de la legitimidad democrática. En el primer caso, la austeridad se aplica por los gobiernos voluntariamente; en el segundo, la 
austeridad se debe aplicar incluso en contra de la voluntad de los mismos, atados como están por el MDA.

Los partidos dominantes de izquierda y derecha que se adhieren a esta reducción artificial de las alternativas han sufrido una sangría de votos. Lamentablemente para el proyecto europeo, la presión sobre los gobiernos de los GIIPs para que abandonen la austeridad proviene de movimientos sociales y partidos radicales, tanto de derechas como de izquierdas, que son cada vez más euroescépticos. Están surgiendo y creciendo partidos que dicen representar a los ciudadanos frente a una élite corrupta formada por una alianza de políticos y banqueros. Entre los objetivos principales de este antielitismo se encuentran los burócratas de Bruselas aunque, como bien expone Schelkle, "sería más pertinente culpar a las democracias nacionales por imponerse entre ellas el diktat [de la Troika]» (2012: 154). Estas plataformas de partidos euroescépticas y antielitistas reclaman más democracia y de mejor calidad para que sea posible la regeneración política. Su compromiso de defensa de la democracia es cré́ble a los ojos de un creciente número de votantes en aquellos países que han recibido la ayuda económica de la Troika, puesto que son los únicos que critican abiertamente la primacía de los intereses económicos sobre el destino de sociedades enteras. En una especie de déjàvu de la época de las negociaciones europeas sobre la fundación, adhesión y unión económica, la extrema derecha se queja de la pérdida de soberanía del estado-nación frente a las instituciones de la UE, mientras que la izquierda radical pone de relieve la pérdida de soberanía de la ciudadanía frente a los mercados financieros.

La izquierda y la derecha dominantes están tan desacreditadas ahora en Grecia que su proporción de votos combinados ha caído desde el $77 \%$ en 2009 al 32 \% en 2012. La implicación de esto es que, si desean estar en el gobierno, tienen que compartir el poder poniéndose de acuerdo para formar una gran coalición. En Italia, la gran coalición entre el partido de centro-izquierda, Partito Democratico - $\mathrm{PD}-$, y el de centro-derecha, Popolo Della Libertà -PDL-, es un hecho desde marzo de 2013. El PD perdió ocho puntos porcentuales en las elecciones generales y el PDL cayó dieciséis puntos. Con estos resultados no había más alternativa que gobernar conjuntamente. En España, la izquierda dominante del psoE está extremadamente desacreditada, con una pérdida del $15 \%$ de su proporción de votos entre 2008 y 2011. Ahora es el turno del descrédito de la derecha, con la intención de voto para el pp a un nivel tan bajo como el 22,5\%, de acuerdo con la encuesta de Metroscopia para El País (11/5/2013), e incluso inferior, el $12,5 \%$, según el barómetro del cis (n. ${ }^{\circ} 2984$, abril de 2013). A menos que 
la situación económica mejore en los próximos tres años, España se dirige hacia un escenario como el griego, en el que los dos partidos dominantes pierden de manera alarmante y simultánea. El caso de Portugal es similar. El Partido Socialista -Ps- perdió ocho puntos porcentuales en las elecciones generales de 2011. Fue sustituido en el gobierno por el partido de centro-derecha, el PSD, igualmente incapaz de mejorar la situación con sus políticas procíclicas. En el verano de 2013 se produjo una crisis de gobierno, debido a los desacuerdos internos en la coalición del gobierno sobre el modo de implementar el Memorando de Acuerdo con la Troika. Durante la crisis política, el presidente portugués pidió a los partidos en el poder y en la oposición que trabajaran conjuntamente en una gran coalición para salir de la crisis económica. Los partidos irlandeses en ejercicio no escaparon tampoco al terremoto político de la crisis. En la elección parlamentaria de febrero de 2011, Fianna Fáil, un partido que parecía "prácticamente inamovible del poder» (ÓMuineacháin y Gallagher 2008: 154), perdió veinticuatro puntos porcentuales y cayó al tercer puesto en cuanto a proporción de votos y escaños por primera vez desde 1932. Se produjo una completa reestructuración del sistema de partidos, que se había mantenido relativamente constante durante los últimos ochenta años. «El eje dominante de diferenciación entre el primer y el segundo partido más grande de la Cámara baja del Parlamento de la República de Irlanda pasó a ser el eje izquierda-derecha, en vez de la tradicional división centro-periferia que llevaba ochenta años separando al FF y al FG» (Hutcheson, 2011: 11). El Partido Laborista irlandés obtuvo la proporción más alta de escaños y votos de su historia. Otro ganador fue el Sinn Féin, que hizo campaña a favor de rechazar el Memorando de Acuerdo con la Troika (Hutcheson, 2011).

Al mismo tiempo, se está produciendo un crecimiento de nuevos partidos, tanto a la izquierda como a la derecha de la izquierda y la derecha dominantes, de manera muy considerable en Grecia -con el partido fascista Amanecer Dorado y el grupo radical de izquierda Syriza- y en Italia -con el Movimento Cinque Stelleque abarca tanto la derecha como la izquierda. En Grecia, en 2012, Syriza obtuvo el 16,78 \% de los votos, en segundo lugar por detrás de Nea Demokratia $(18,85 \%)$, el ganador pírrico de las elecciones. De manera similar, en Italia, el partido м5s de Beppe Grillo fue el más votado en las últimas elecciones generales, celebradas en febrero de 2013, con el 25,5 \% de los votos. El Partito Democratico obtuvo el 25,4\%, aunque la coalición de izquierdas superó al м5s en cuatro puntos porcentuales $(29,5 \%)$, por lo que obtuvo el premio de mayoría que otorga el sistema electoral italiano al partido con mayor número de votos. La ca- 
racterística común de estos partidos es su rechazo a los MdA y su posición favorable a debatir la posibilidad de salir del euro.

En última instancia, la capacidad de implementar un ajuste fiscal depende de la voluntad de la ciudadanía para tolerarlo. Estos programas requieren cambios drásticos en un breve periodo de tiempo y, cuanto más se tarde en mejorar la situación económica de los ciudadanos, más difícil será para sus gobiernos pedir el apoyo de la sociedad para soportar con paciencia la austeridad. La imposición de la austeridad ha roto el vínculo entre las demandas de los ciudadanos y la actuación de los gobiernos. Cada vez más, los nuevos partidos y movimientos representan este espacio en términos de «nosotros» frente a «ellos», la ciudadanía contra la élite, la ciudadanía contra Europa, y esto es precisamente lo más irónico: con sus decisiones, los gobiernos nacionales electos otorgan credibilidad a esta interpretación.

\section{LA PROGRESIVA FRACTURA DEMOCRÁTICA EN LA UE}

¿Cuáles son las consecuencias para la democracia de la enorme brecha existente en la eurozona entre los países acreedores y los deudores? De acuerdo con Panagiotarea, la crisis de la deuda «se ha convertido en una crisis de confianza» (2013: 173). Los datos del Eurobarómetro muestran que tiene razón. Los ciudadanos de los países endeudados han perdido por completo la confianza en las instituciones de representación política, tanto nacional como europea. Asimismo, los europeos de la periferia han dejado de creer en las instituciones europeas no electas, como la Comisión y el BCE. Más preocupante todavía es el gran descenso sufrido en los niveles de satisfacción con el funcionamiento de la democracia nacional y europea. Esta crisis de confianza, no obstante, no ha afectado igualmente a las democracias del núcleo de la eurozona.

Para ver esto, echemos un vistazo a los datos del Eurobarómetro de entre 2002 y 2013. He agrupado a los países de la eurozona en dos categorías no exhaustivas: por una parte, los países GIIPs; por otra parte, el país núcleo de la Eurozona, Alemania, con sus aliados favorables a la austeridad -Finlandia, Países Bajos y Austria. Las siguientes cifras representan medias para cada grupo. Los gráficos del 1 al 4 muestran la evolución de la confianza en las instituciones nacionales y de la satisfacción con la democracia nacional. La confianza se mide como porcentaje de encuestados que dicen confiar en la institución. La satisfacción con la democracia se mide como 
porcentaje de encuestados que dicen estar muy o bastante satisfechos con la democracia.

Los picos de subidas y de bajadas en los gráficos del 1 al 3 indican que los niveles de confianza en las instituciones representativas están muy afectados por el contexto. La proximidad a unas elecciones, los escándalos políticos y las crisis económicas e internacionales son todos ellos factores que tienen un impacto directo - positivo o negativo- en los niveles de confianza. A pesar de esta trayectoria llena de altibajos, los gráficos del 1 al 3 muestran claramente la aparición de una brecha en la opinión pública europea entre los países GIIPs y los del núcleo desde el estallido de la crisis. Desde 2002, las diferencias en la confianza entre el núcleo y la periferia nunca llegaron a superar el $10 \%$; diez años después, existe una brecha del $38 \%$ en la confianza en los gobiernos nacionales, del $36 \%$ en la confianza en el parlamento nacional y del $27 \%$ en la confianza en los partidos. Esto es lo que denomino «la fractura democrática».

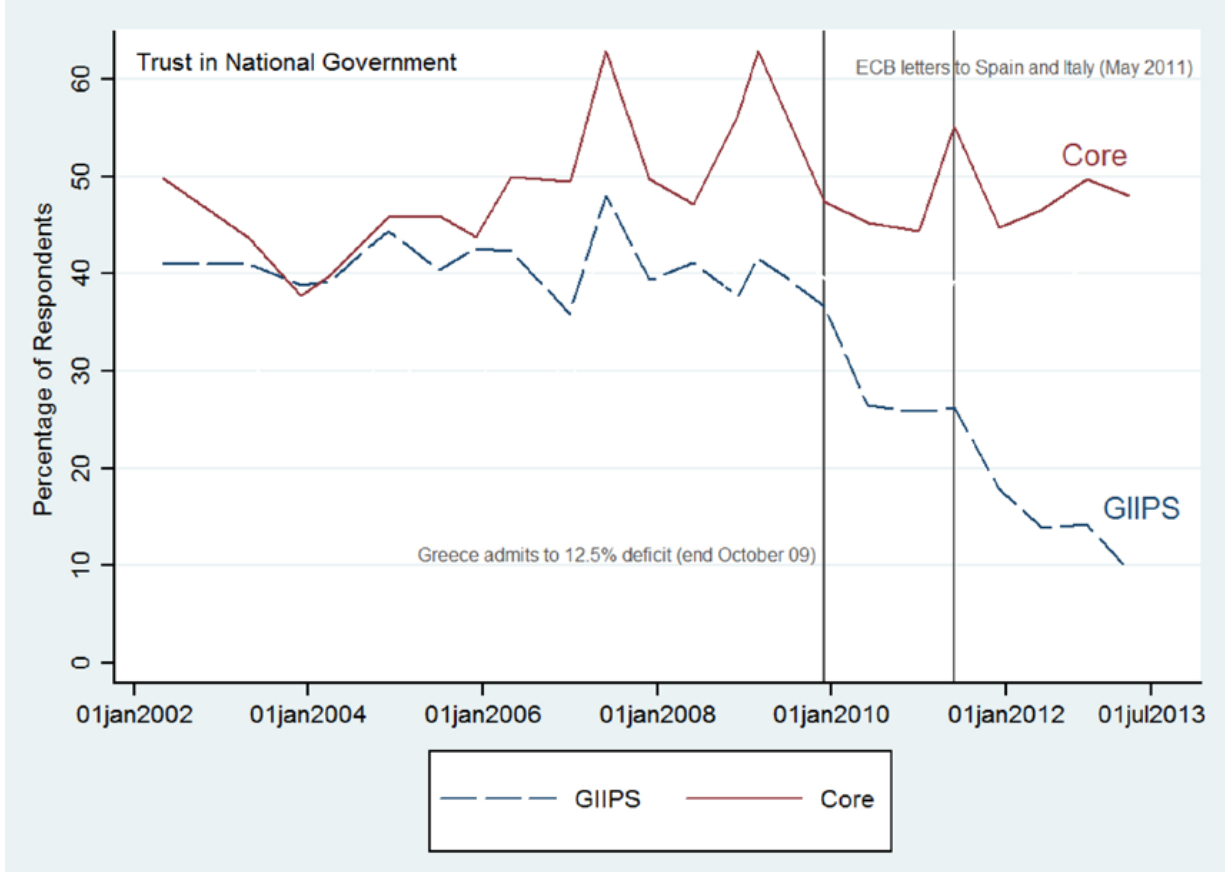

\section{Gráfico 1}

Evolución de la confianza en el gobierno nacional, Eurobarómetro 2002-2013 


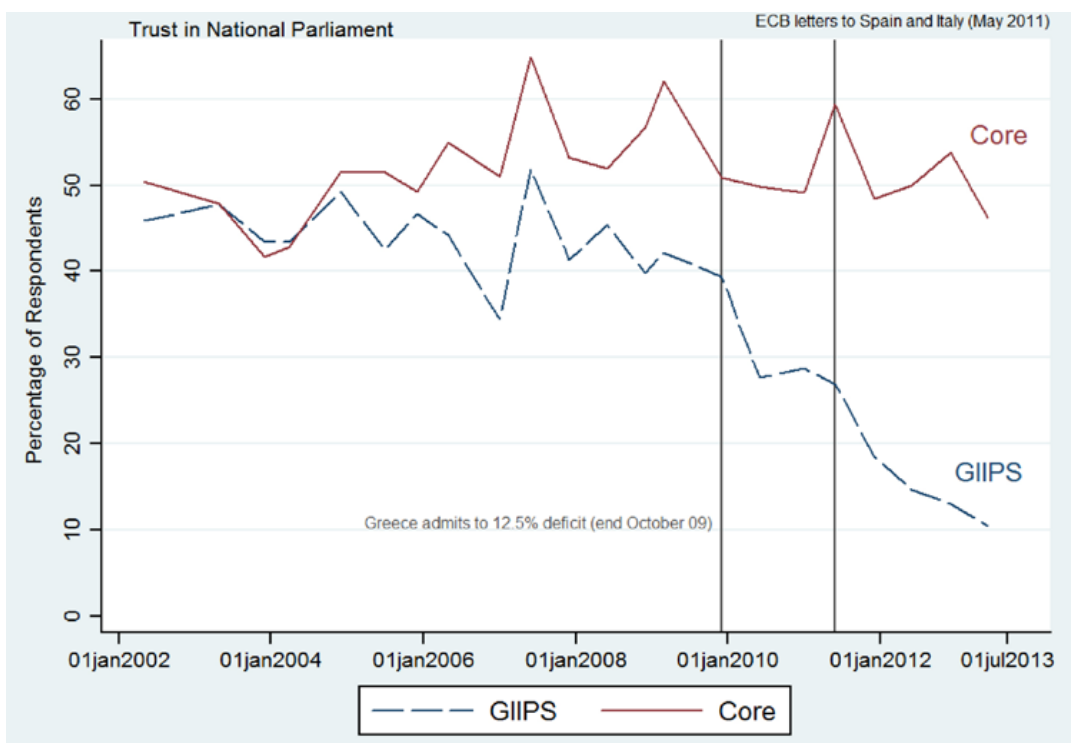

Gráfico 2

Evolución de la confianza en el parlamento nacional, Eurobarómetro 2002-2013

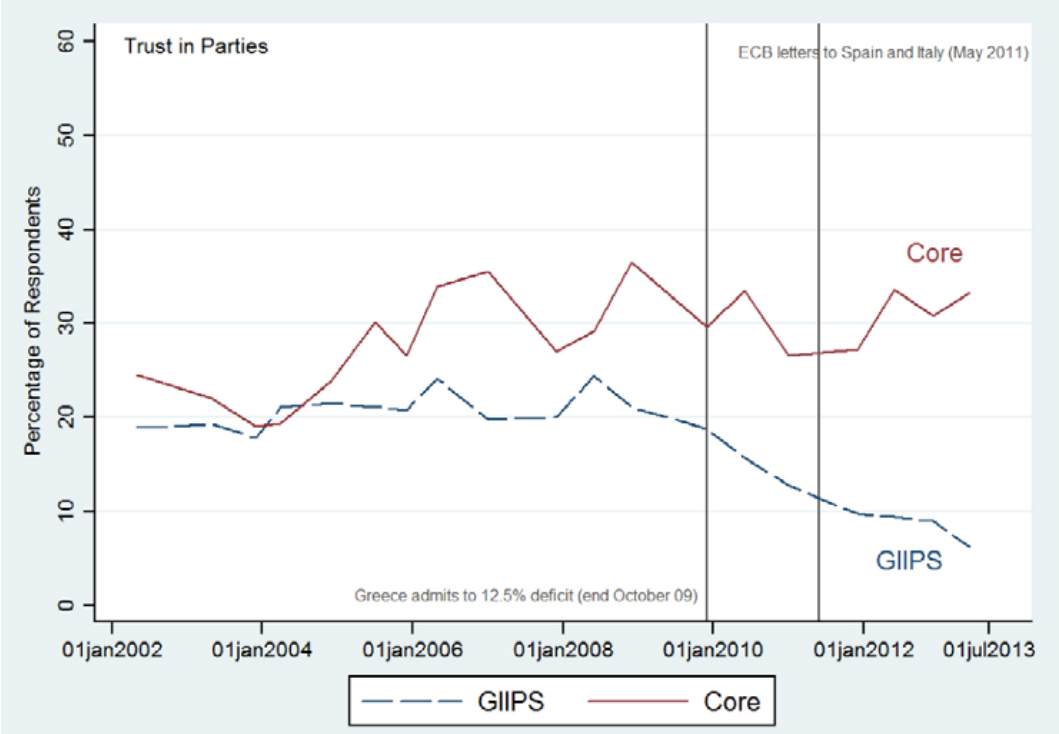

Gráfico 3

Evolución de la confianza en los partidos políticos, Eurobarómetro 2002-2013 


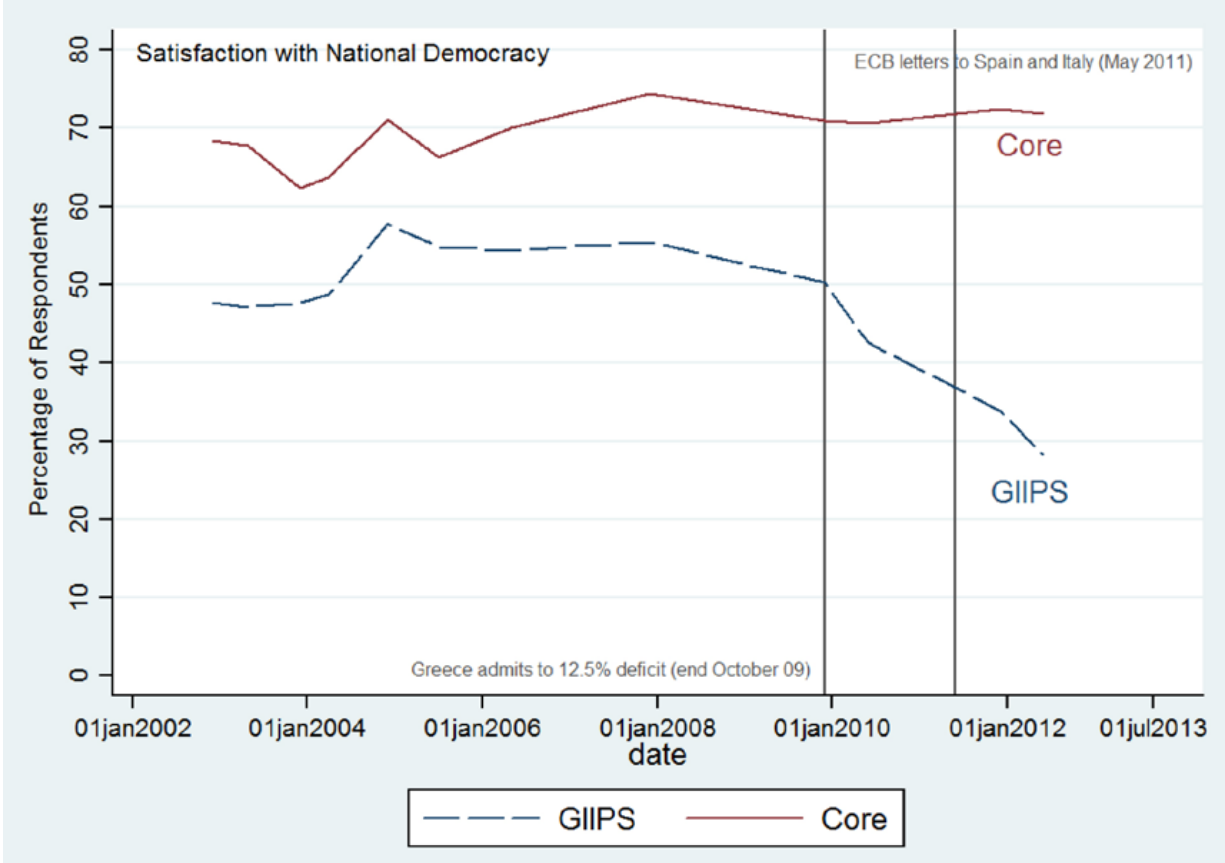

Gráfico 4

Evolución de la satisfacción con la democracia, Eurobarómetro 2002-2013

Los niveles de confianza en las instituciones representativas cayeron de manera alarmante en estos años en los países GIIPs. A los partidos nunca se les había tenido en gran consideración y, por ese motivo, la caída en la confianza en los partidos fue la más pequeña, pero en 2013 estaba a niveles mínimos: menos de 1 de cada 10 encuestados confiaba en sus partidos nacionales. La confianza en los gobiernos y parlamentos nacionales sufrió una caída espectacular, especialmente desde el primer rescate a Grecia en 2010. En 2013 la confianza en estas instituciones se encuentra al $10 \%$, un nivel casi tan bajo como el de los partidos.

En Alemania y sus aliados, la confianza política se ha mantenido por encima de sus niveles de 2002, desde que Lehman Brothers entró en quiebra en septiembre de 2008. Tanto la confianza en los gobiernos como en los partidos políticos tuvo un pico entre septiembre de 2008 y febrero de 2009 , período en el que los gobiernos nacionales estaban imple- 
mentando reformas anticíclicas y en el que los políticos de los estados miembros hablaban de la necesidad de reinventar el capitalismo. Después de este pico de confianza, los niveles bajaron en 2010 y 2011, los años de las ayudas económicas a los países GIIPs, pero volvieron a crecer en 2012, especialmente el de la confianza en los partidos políticos, que aumentó del $25 \%$ en noviembre de 2011 a casi el $33 \%$ en junio de 2012 , y de nuevo en junio de 2013. La satisfacción con la democracia evolucionó de manera parecida. La tendencia estable en el núcleo y el colapso en la periferia son claros, como muestra el gráfico 4. En 2013 los países del núcleo habían recuperado e incluso superado los niveles de confianza en la política y la satisfacción con el sistema democrático de los que disfrutaban diez años atrás.

Esta fractura democrática no se reprodujo en igual medida cuando se mira a la confianza en las instituciones europeas. Los gráficos del 5 al 8 muestran la evolución en los niveles de confianza en la Comisión Europea, el Banco Central Europeo, el Parlamento Europeo y, finalmente, la Unión Europa en su conjunto. Aunque existe una distancia entre los niveles de confianza existentes en el núcleo y los de la periferia, ésta se debe fundamentalmente al hecho de que la caída en los niveles de confianza tuvo lugar a un ritmo más rápido entre los países GIIPs que entre los del núcleo de la eurozona. Sin embargo, esta tendencia es evidente para ambos grupos. La confianza en las instituciones europeas decreció, independientemente de si dichas instituciones son representativas -el Parlamento Europeo- o no -el BCE-. El declive más drástico lo experimentó la Unión Europea en su conjunto. Desde 2010, cuando 1 de cada 2 ciudadanos, tanto de países núcleo como de la periferia, confiaba en la uE, la confianza se redujo a un mero $20 \%$ en la periferia y al $35 \%$ en el núcleo en 2013. 


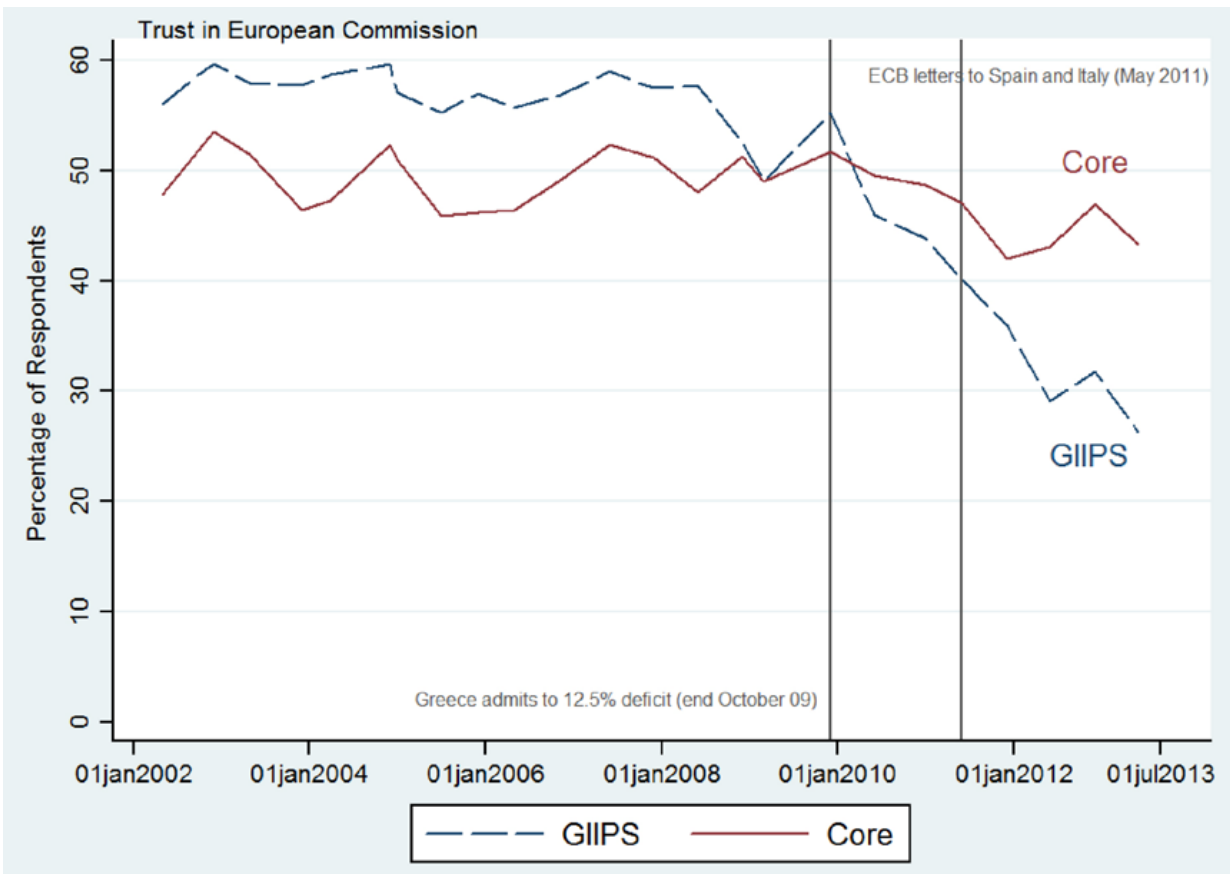

Gráfico 5

Confianza en la Comisión Europea, Eurobarómetro 2002-2013

Antes del estallido de la crisis, los ciudadanos de los países GIIPs confiaban en las instituciones europeas más que los ciudadanos de los países núcleo -con excepción del всE. Después de 2008, esto cambió. El núcleo se hizo más europeísta que la periferia. La buena noticia para el proyecto europeo es que los ciudadanos de los países GIIPs en 2013 aún seguían confiando más en las instituciones europeas que en sus propias instituciones nacionales, y que la institución que más confianza generaba entre los ciudadanos de los países GIIPs era el Parlamento Europeo, quizás porque está menos conectado, a ojos de los ciudadanos, con los elevados costes sociales derivados de las políticas de austeridad. El más elevado de estos costes es el desempleo y los efectos que lo acompañan: pobreza y exclusión. De acuerdo con Eurostat, entre 2008 y 2013 el desempleo aumentó en Grecia en 19,3 puntos hasta llegar al 27,6; en España, en 16,9 
puntos hasta llegar a 26,3; en Portugal, en 7,8 puntos hasta el $16,5 \%$; y en Irlanda, en 7,4 puntos hasta el 13,8. Como Roth et al. (2013) han demostrado, estos niveles insostenibles de desempleo constituyen los factores que mejor explican el descenso de la confianza en las instituciones nacionales y europeas.

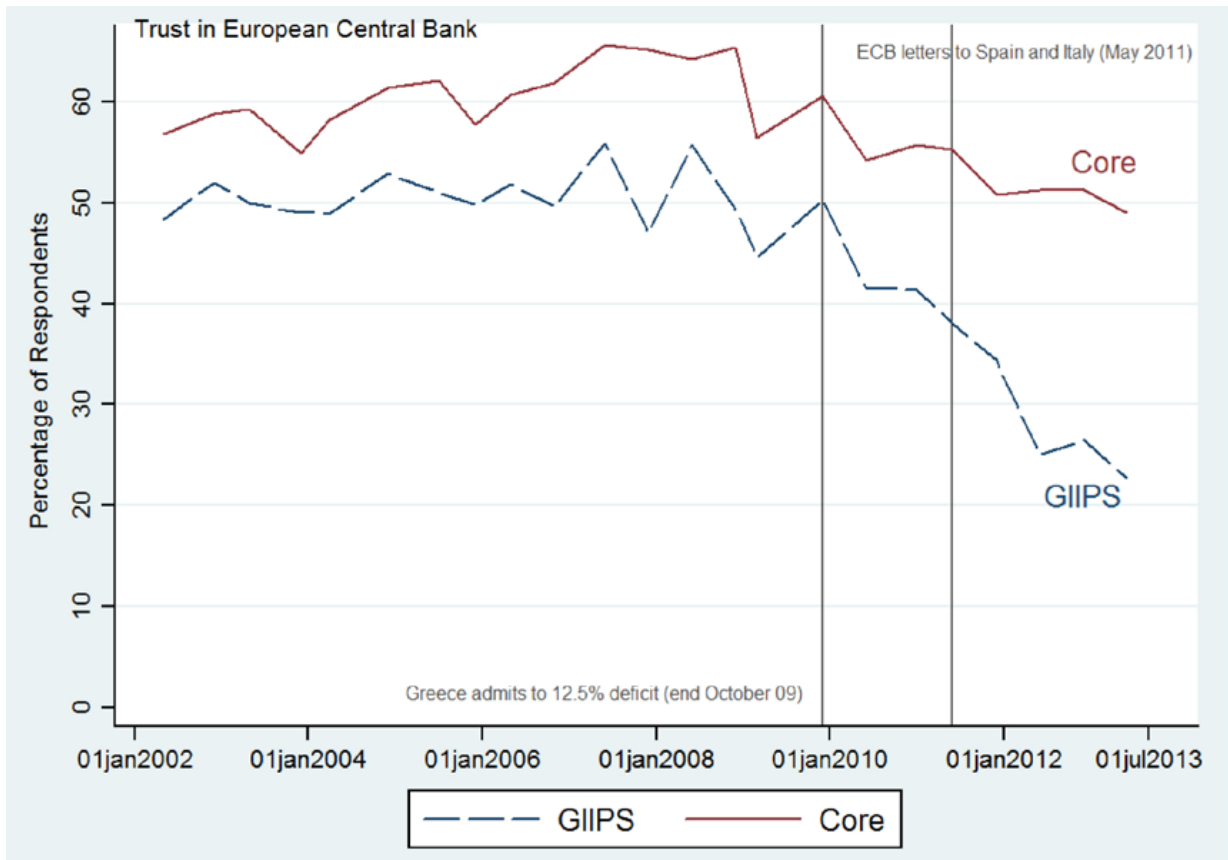

Gráfico 6

Confianza en el Banco Central Europeo, Eurobarómetro 2002-2013 


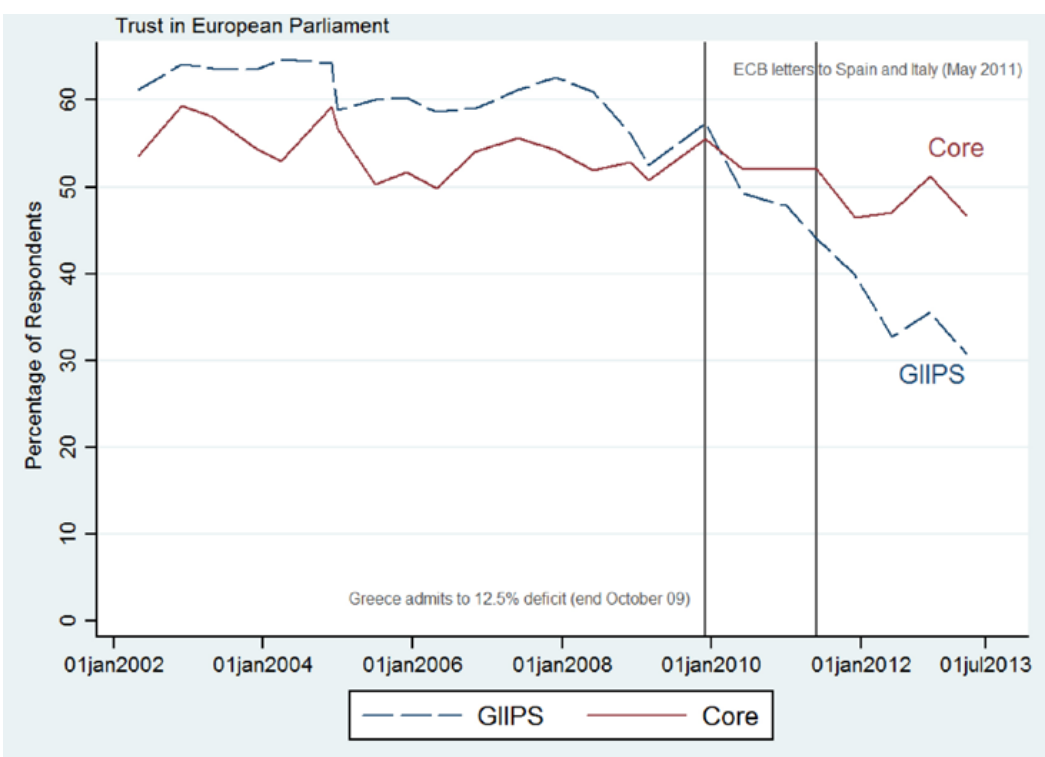

\section{Gráfico 7}

Confianza en el Parlamento Europeo, Eurobarómetro 2002-2013

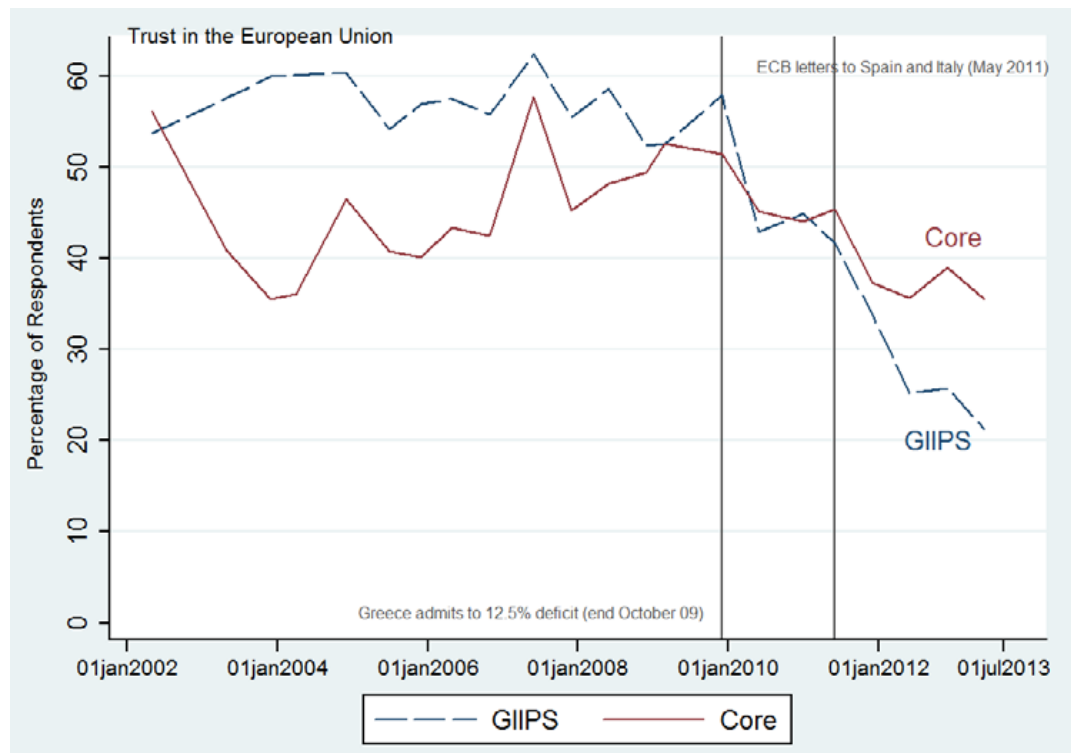

Gráfico 8

Confianza en la Unión Europea, Eurobarómetro 2002-2013 
Analicemos ahora más en detalle el caso de la locomotora de la economía europea, Alemania. Aquí nos encontramos con un desarrollo preocupante. Mientras que la confianza en las instituciones nacionales experimentó una tendencia al alza -aunque con altibajos-, la confianza en las instituciones europeas descendió -gráficos 9 y 10. Los niveles más bajos de confianza en el gobierno, parlamento y partidos nacionales tuvieron lugar precisamente entre 2002 y 2004, periodo durante el cual Alemania era «la enferma de Europa», cuando atravesaba una recesión económica que llevó al país al incumplimiento del Tratado de Maastricht, y que sólo finalizó con el paquete de reformas estructurales implementadas por la coalición SDP/ Verdes, conocido como la Agenda 2010. Desde 2008, en contraposición, parece haber habido cierta reivindicación nacional en juego, por la que los ciudadanos alemanes recompensaban a sus instituciones representativas por la defensa de sus intereses y preferencias frente a las de otros socios europeos. El año 2009 fue el primero en el que se invirtió la tendencia a la baja en los niveles de voto de los dos partidos de masas alemanes, el SPD -socialdemócratas- y la CDU-CSU -cristiano-demócratas-, que se venía observando desde mediados de los 70. En las dos últimas elecciones generales, en 2009 y en 2013, la participación de voto combinado de CDU y SDP creció de forma considerable, aunque la mayor parte de este crecimiento pertenecía a la cDU.

Los ciudadanos alemanes se sienten representados por sus instituciones nacionales por varios motivos. En primer lugar, los indicadores macroeconómicos son buenos, incluso extremadamente buenos en comparación con los de otros países de la ue. Según los datos de Eurostat, el crecimiento volvió durante el segundo trimestre de 2013 -0,7 \%- y el país registra la segunda tasa de desempleo más baja de la uE después de Austria -5,4 \%. En Alemania esto se reivindica como el resultado de las reformas de la Agenda 2010. En segundo lugar, muy en relación con el primero, los costes sociales de la austeridad no son tan visibles en Alemania como los son en los países que han sido intervenidos. Por lo tanto, los alemanes no tienen problemas para ver la austeridad como algo necesario, ya que aún no son ellos los que la sufren en mayor medida. En tercer lugar, las principales preocupaciones de los alemanes son la deuda pública y la inflación -Eurobarómetro 79, julio de 2013-, por lo que las políticas de austeridad encajan bien con sus preferencias. En cuarto lugar, los alemanes sufren la denominada «fatiga del rescate»: se oponen a más rescates, así como a la creación de eurobonos ${ }^{3}, y$

3 Solo el $26 \%$ de los alemanes está a favor de los eurobonos (Eurobarómetro 79, julio de 2013), la cifra más baja entre los 27 de la uE, seguidos por los británicos (33 \% a favor). En contraposición, el 94 \% 
el Gobierno alemán responde claramente a estas preferencias, haciéndolas política oficial.

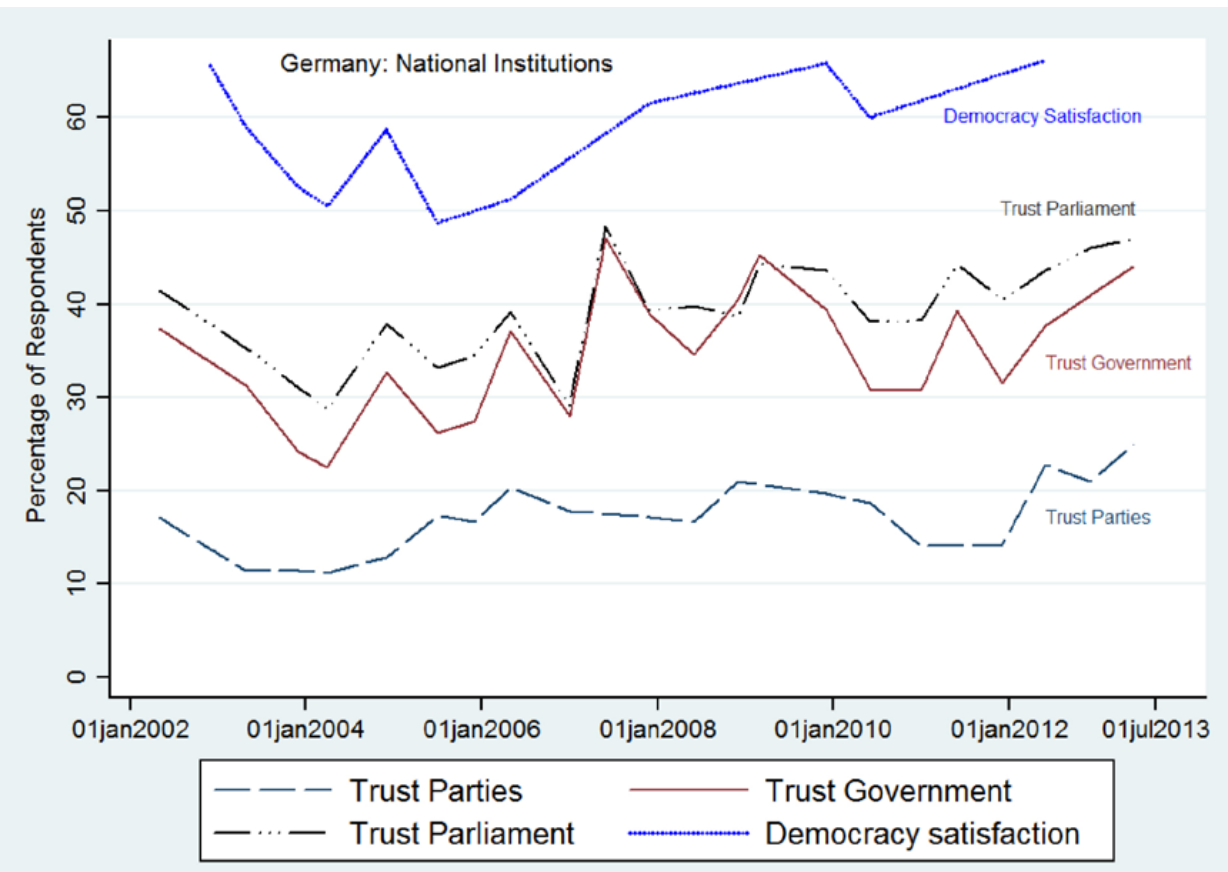

Gráfico 9

Evolución de la confianza en las instituciones nacionales en Alemania, Eurobarómetro 2002-2013

de los griegos y españoles, el $94 \%$ de holandeses y austríacos, el $93 \%$ de los finlandeses y el $90 \%$ de los franceses están a favor de los eurobonos. 


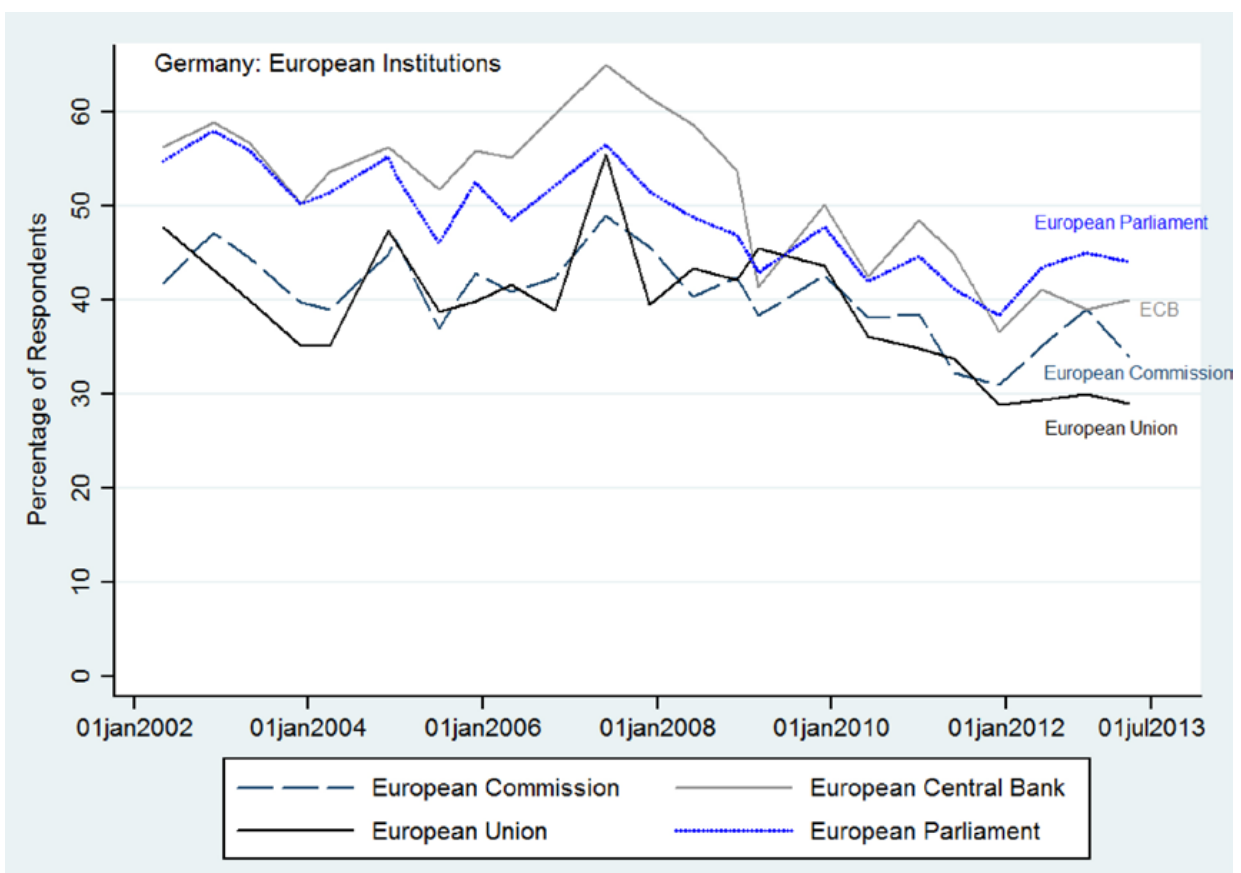

Gráfico 10

Evolución de la confianza en las instituciones europeas en Alemania, Eurobarómetro 2002-2013

Igual que podemos hablar de un núcleo y una periferia económicos en la zona euro, también podemos referirnos a un núcleo y una periferia políticos. Los ciudadanos de los países GIIPs han perdido la confianza en las instituciones representativas en todos los niveles, nacionales y europeos, a la vez que están muy insatisfechos con el funcionamiento de la democracia. La crisis de la deuda ha dado origen a una profunda crisis política. Los ciudadanos de los países núcleo de la eurozona, en contraste, han recuperado la confianza en sus instituciones nacionales, mientras que disminuye su confianza en las instituciones europeas. La crisis de la deuda ha dado un empuje a las políticas democráticas nacionales a expensas de Europa y el proyecto europeo. 


\section{OBSERVACIONES FINALES}

Detrás de la crisis de la deuda soberana en la zona euro se oculta una ironía histórica. Grecia, Portugal y España querían ser parte de la UE, convencidos de que eso protegería sus incipientes democracias. En aquel momento, Grecia, España y Portugal veían en la ue todo aquello que no tenían: democracias estables, prosperidad económica y justicia social.Y ahí reside la ironía. La pertenencia a la Unión Europea está socavando ahora la legitimidad de esas mismas democracias que supuestamente iba a estabilizar. Se ha establecido una «democracia sin alternativas» bajo las reglas de los $\mathrm{Md}_{\mathrm{A}-a u n-}$ que incluso los países que no han firmado un mdA todavía, como Italia, reciben duras presiones para seguir las medidas de austeridad. Son democracias sin elección, porque la alternancia en el poder ni puede producir ni produce un cambio de la política económica. Los gobiernos electos ni son libres para elegir entre alternativas de políticas económicas ni son lo bastante fuertes para forzar a sus socios de la eurozona a un cambio de marcha. Como resultado, todo lo que le queda a los gobiernos de los GIIPs por decidir es, por un lado, los detalles en torno a qué recortar y, por otro lado, las medidas que van a usar para responder a la oposición en las calles. Las democracias de los países GIIPS están en compás de espera, paralizadas, esperando a que la "política» haga su trabajo. Las elecciones siguen siendo libres y justas; asimismo, partidos más pequeños, tanto nuevos como antiguos, han ofrecido alternativas a los $\mathrm{md}$ - $\mathrm{O}$ a la austeridad- a los electorados de los países GIIPs. Por lo tanto, todavía existe la esperanza de que la democracia, parafraseando a De Tocqueville, se rescate a sí misma.

En contraposición a lo anterior, se podría afirmar que la falta de elección de los gobiernos no es producto de la crisis. La reducción de las alternativas en política económica ha sido parte del diseño institucional de la UE, al menos desde Maastricht, y las quejas al respecto se han dado sólo en los márgenes del sistema político. La mayoría del electorado europeo, especialmente en los países GIIPs, secundó esta reducción e incluso la alabó. Es justo reconocerlo. Como ya he dicho desde el principio, la ausencia de elección en los países GIIPs ha sido autoinfligida, llevada a cabo mediante procedimientos democráticos -todos los Tratados y acuerdos de la uE se aprobaron bien por los parlamentos nacionales o mediante referéndum, según el país de que se trate. No importa cuánto les guste a los políticos de los países GIIPs enmarcar la situación económica como una imposición del exterior; ellos saben que ostentan dos roles -el de estado-nación y el de estado-miembro- y que, como estados miembros de la uE, son una parte 
responsable de precisamente aquellas instituciones que ahora les están imponiendo políticas de austeridad.

La reducción de la discrecionalidad de los gobiernos nacionales no provocó indignación antes de la crisis, debido a que nunca antes había venido acompañada de unos costes sociales tan visibles, generalizados y profundos. Durante los períodos de crecimiento económico, con bajos niveles de desempleo y la ilusión de riqueza que aportaba el consumo basado en la deuda, los electorados europeos ni veían ni sentían la falta de autonomía de sus gobiernos. Los políticos nacionales contribuían de manera conveniente a mantener a sus electorados en la ignorancia de lo que realmente ocurría. El diseño neoliberal que se encontraba detrás de la unión monetaria se ocultaba discretamente con cuentos de prosperidad en un mundo globalizado. La reducción de las alternativas económicas contaba con la bendición de los demoi europeos. Sólo la crisis del euro ha demostrado hasta dónde han renunciado los gobiernos democráticos, en el caso de la uE colectivamente más que de forma individual, a su autonomía frente a los mercados y a su capacidad de implementar políticas sociales en tiempos difíciles. Cuando la ausencia de elección provoca injusticia social y un repentino recrudecimiento de la desigualdad, la ciudadanía se vuelve contra ello, porque es algo que, esta vez sí, se ve y se siente.

El problema de la austeridad para la democracia reside más en el hecho de que tiene unos efectos redistributivos enormes que perjudican a la mayoría de la población que en el hecho de que está impuesta a los estados miembros por parte de las instituciones de la UE. Si las personas estuvieran en contra de la imposición a los gobiernos nacionales per se, se habrían sublevado hace mucho tiempo. Contra lo que se sublevan es contra la injusticia social, el desempleo generalizado, la exclusión y una generación perdida, que coincide en el tiempo con una élite socio-económica acomodada que cada vez lo es más y que no se enfrenta a las consecuencias de su comportamiento irresponsable, el cual ha conducido al colapso financiero. Pensemos en un argumento contrafáctico. Supongamos que los Gobiernos de los GIIPS están presos de los intereses financieros y, como reacción a la crisis de 2008 , imponen medidas de austeridad duras en sus países sin hacer caso a la oposición generalizada por parte de su ciudadanía. Supongamos además que, testigos del riesgo que supone esta estrategia para la estabilidad política de estos países, y siendo fieles a los valores sociales y democráticos de Europa, la Troika fuerza a dichos gobiernos de los países GIIPs a cambiar de táctica y a introducir medidas de expansión fiscal que reducirían los costes sociales de la crisis. ¿Protestarían los ciudadanos de 
los países GIIPs contra la expansión social impuesta desde Bruselas del modo que han protestado contra la austeridad? Probablemente no lo harían. El problema no es la imposición desde fuera, puesto que los países GIIPS son estados miembros de la UE tanto como cualquier otro país y son co-responsables de las decisiones tomadas en el marco de la uE. El problema es la austeridad y sus consecuencias para la justicia social y, con el tiempo, para la estabilidad política de las democracias europeas.

El debate en torno a si una democracia sin alternativas, pero con apoyo popular, es realmente una democracia o no es un debate abierto. Lo que es seguro, no obstante, es que una democracia sin posibilidad de elección ni apoyo popular es una democracia vulnerable a las revueltas populares y a la inestabilidad. La legitimidad de la democracia no se basa únicamente en el procedimiento, sino también en los resultados. Cuando el procedimiento -es decir, unas elecciones libres y justas- garantiza que exista una posibilidad futura de que gane el partido que aboga por la justicia social, entonces el procedimiento y la justicia social se refuerzan entre sí como fuentes de legitimidad. De manera contraria, si el procedimiento no brinda una oportunidad a la justicia social, la democracia pierde legitimidad en los dos frentes, como procedimiento y como contenido.

Todavía no se ha logrado explicar correctamente cómo es posible pedir a países con niveles de desempleo como los de Grecia y España que suban los impuestos y recorten las transferencias sociales sin debilitar sus respectivas democracias, ni por parte de las instituciones nacionales, ni por parte de las de la uE. Las instituciones europeas y los países núcleo de la eurozona no parecen estar preocupados por las consecuencias políticas de la austeridad en las democracias de los GIIPs. Parecen actuar en la creencia de que la inestabilidad será pasajera y de que pronto todo volverá a la normalidad. Ni siquiera los gobiernos de los países GIIPs parecen estar preocupados. Si lo están, resulta difícil explicar por qué no crean un frente unido contra la austeridad en la UE. En cambio, la crisis económica ha intensificado las soluciones, estrategias y sentimientos nacionales -y nacionalistasmientras que, al mismo tiempo, la autonomía de los gobiernos nacionales se ha visto más reducida aún si cabe. Los gobiernos del núcleo de la zona euro liderados por Alemania están promoviendo la condicionalidad -préstamos a cambio de ajustes- a expensas de la solidaridad interterritorial, y un acuerdo intertemporal entre la satisfacción de los electorados nacionales ahora a cambio de más tecnocracia mañana. Esta mezcla incongruente de nacionalismo populista y tecnocracia neoliberal no parece un instrumento bien pensado y coherente con el que afrontar la fractura económica 
y democrática que ha emergido en el seno de la uE. Los gobiernos nacionales de todos los países de la ue harían mejor en escuchar a la ciudadanía de la Unión Europea en su conjunto, y no sólo a sus propias ciudadanías nacionales, si es que desean que haya esperanza para una ue democrática.

\section{BIBLIOGRAFÍA}

Acemoglu, D. y J. Robinson (2006): Economic Origins of Dictatorship and Democracy, Cambridge University Press.

Ansell, B. (2012): «Crisis as Political Opportunity? Partisan Politics, Housing Cycles, and the Credit Crisis» en Bermeo, N. y J. Pontusson (eds.) (2012): Coping with Crisis. Government Reactions to the Great Recession, Nueva York, Russel Sage Foundation.

Armingeon, K. y L. Baccaro (2012): «The Sorrows of Young Euro:The Sovereign Debt Crisis of Ireland and Southern Europe» en Bermeo, N. y J. Pontusson (eds.) (2012): Coping with Crisis. Government Reactions to the Great Recession, Nueva York, Russel Sage Foundation.

BARnes, L. y A. Wren(2012): "The Liberal Model in (the Crisis: Continuity and Change in Great Britain and Ireland» en Bermeo, N. y J. Pontusson (eds.) (2012): Coping with Crisis. Government Reactions to the Great Recession, Nueva York, Russel Sage Foundation.

Bermeo, N. y J. Pontusson(eds.) (2012): «Coping with Crisis: An Introduction» en Bermeo, N. y J. Pontusson (eds.) (2012): Coping with Crisis. Government Reactions to the Great Recession, Nueva York, Russel Sage Foundation.

CAmeron, D.R. (2012: «European Fiscal Responses to the Great Recession» en Bermeo, N. y J. Pontusson (eds.) (2012): Coping with Crisis. Government Reactions to the Great Recession, New York, Russel Sage Foundation.

Chang, H.J. (2010): 23 Things They Don't Tell You about Capitalism, Londres, Penguin Books.

DAHL, R. (1989): Democracy and its Critis, New Haven y Londres, Yale University Press.

Downs, A. (1957): An Economic Theory of Democracy, Nueva York, Harper \& Row.

Friedman, T. (2000): The Lexus and the Olive Tree, Nueva York, Anchor Books.

Garret, G. (1999): «Global Markets and National Politics: Collision Course or Vicious Circle?», International Organization, 52, pp. 787-824. 
HeLd, D. (2000): «Regulating Globalization? The Reinvention of Politics», International Sociology, 15, pp. 394-408.

Hutcheson, D. (2011): "The February 2011 Parliamentary Election in Ireland», Working Papers in British-Irish Studies, 109, Dublin, Institute of BritishIrish Studies.

Judt, T. (2010): Ill Fares the Land, Nueva York, The Penguin Press.

Kuingemann, H.D., R. I. Offerbert y I. Budge (1994): Parties, Policies and Democracy, Boulder, Co., Westview Press.

KRUGMAN, P. (2009): Return of Depression Economics and the Crisis of 2008, Nueva York, W.W.Norton.

Maravall, J.M. (2013): Las Promesas Políticas, Madrid, Galaxia Gutenberg S.L.

Ó Muineacháin, S. y M. Gallagher (2008): "The Parliamentary Election in Ireland, May 2007», Electoral Studies, 27, pp. 151-154.

Panagiotarea, E. (2013): Greece in the Euro. Economic Delinquency or System Failure?, Wivenhoe Park, Colchester, ECPR Press.

Przeworski, A. (2010): Democracy and the Limits of Self-government, Cambridge University Press.

RIKER, W. (1982): Liberalism Against Populism:A Confrontation Between the Theory of Democracy and the Theory of Social Science, Long Grove, Illinois, Waveland Press, Incorporated.

Rodrick, D. (2011): The Globalization Paradox. Nueva York, W.W. Norton \& Company.

Roth, F.,Felicitas, N.L. y T. OTter(2013): «Crisis and Trust in National and European Union Institutions - Panel Evidence for the EU, 1999 to 2012», EUI Working Paper RSCAS, 2013/31, Fiesole.

SCHARPf, F.W. (2011): «Monetary Union, Fiscal Crisis and the Preemption of Democracy», LEQS Annual Lecture Paper 36/2011.

SCHATtscheinder, E.E. (1975): The Semi-Sovereign People. A realist's View of Democracy in America, Cengage Learning.

SChelkle, W. (2012): «Policymaking in Hard Times: French and German Responses to the Eurozone Crisis» en Bermeo, N. y J. Pontusson (eds.) (2012): Coping with Crisis. Government Reactions to the Great Recession, Nueva York, Russel Sage Foundation.

Stiglitz, J. (2012): The Price of Inequality, Nueva York, W.W. Norton \& Company.

Van Middelaar, L. (2013): The Passage to Europe, New Haven y Londres, Yale University Press. 